\title{
EFFECT OF HEALTH LITERACY ON TREATMENT RESULTS OF TYPE-2 DIABETES MELLITUS PATIENTS ADMITTED FOR INSULIN PEN USE EDUCATION
}

Sumeyye TUNA GUNER ${ }^{1}$, Hakan DEMIRCI ${ }^{2}$

'Osmangazi \# 31 Sevki Agirgiden Family Health Center, Bursa, TURKEY

${ }^{2}$ Department of Family Medicine, University of Health Sciences Turkey Bursa Yuksek Ihtisas Training and Research Hospital, Bursa, TURKEY

\begin{abstract}
Aim: In this study we aimed to evaluate the cognitive status of diabetes mellitus patients referred to an educator nurse for subcutaneous injection treatment education and to measure their health literacy level and compare the findings with treatment results.

Methods: The study population consisted of 200 volunteer Type2 diabetes mellitus patients over age 18 receiving subcutaneous injection (insulin or exenatide) treatment who were admitted to the SBU Bursa Yuksek Ihtisas Training and Research Hospital diabetes education outpatient clinic between January 2018 and February 2018. The Standardized Mini-Mental State Examination and the European Health Literacy Scale Questionnaire were used. A face-to face interview method was used for data collection.HbA1c values of patients were recorded at the time of admission for insulin pen use education, and $\mathrm{HbA} 1 \mathrm{C}$ values of the patients coming for diabetes outpatient control 3 months after the training were also recorded.

Results: From the results of the study, the total rate of participants with insufficient/limited general health literacy was $83 \%$. The incidence of dementia was $24 \%$ in the same population. There was a linear relationship between general health literacy status and mini-mental test scores. The decrease in $\mathrm{HbA} 1 \mathrm{c}$ levels of patients receiving insulin pen education was greater in the group with sufficient health literacy and normal cognitive functions.

Conclusions: Impairment of cognitive functions and low health literacy levels were assessed as obstacles to management of the disease in diabetes mellitus cases receiving injection education. Consideration of these circumstances in patient education could positively affect treatment outcomes.

Keywords: Health literacy, diabetes mellitus, dementia, insulin pen education, HbA1c
\end{abstract}

Corresponding Author: Hakan DEMIRCI drhakandemirci@hotmail.com

Received: April 10, 2021; Accepted: April 16, 2021; Published Online: April 23, 2021

Cite this article as: Tuna Guner, S. \& Demirci, H. (2021). Effect of Health Literacy on Treatment Results of Type-2 Diabetes Mellitus Patients Admitted for Insulin Pen Use Education. European Health Literacy Journal 1(1), 22-32. 


\section{Introduction}

Diabetic patient education is necessary to make the individual feel better, keep the disease under control, protect him/her against possible side effects, reduce treatment mistakes and treatment expenses, and to increase the knowledge and experience of the patient to make him/her capable of using new technologies (1).

Health literacy $(\mathrm{HL})$ can basically be defined as the patient's understanding and interpretation of medical information and behaving accordingly. $\mathrm{HL}$ is a holistic concept that requires the ability to define the individual's health, to know about his/her illness, to make appropriate decisions about his/her health, and to know how to use the health system and how to benefit from it, rather than just reading and understanding information (2).

Baker et al. found that insufficient health literacy skills are independently associated with increased mortality risk among senior adults in the society (3). It is well known that unnecessary hospital charges increase, time of stay in the hospital is prolonged and the rate of unnecessary examinations increase in individuals with insufficient and limited health literacy levels compared to those with sufficient health literacy levels (4). Similarly, hospitalization rates were found to be higher for individuals who were admitted late to the health system due to insufficient and limited health literacy levels (5). As a conclusion, insufficient functional health literacy was found to be a serious obstacle to the education of patients on chronic diseases.

In the study performed by Mark V. Williams et al. with diabetes patients, the aim was to assess the relationship between $\mathrm{HL}$ level of patients, their chronic diseases and their awareness about treatments. Patient consciousness levels concerning their diseases were tested by asking them 10 diabetes questions considering the main elements in the education materials on these diseases. $94 \%$ of the individuals with high health literacy level knew the hypoglycemic symptoms, whereas this rate was reported as $55 \%$ for individuals with low or insufficient HL (6). In another study evaluating the relationship between $\mathrm{HL}$ level and hemoglobinA1c, it was found that glycemic control was worse and hemoglobin $\mathrm{A} 1 \mathrm{C}$ values were two times greater in individuals with low or limited HL levels (7).

Low health literacy is also associated with increased dementia risk (8). In a previous study it was shown that a decrease in cognitive function in the elderly is associated with a decrease in health literacy, impairment of physical health and a higher rate of depression (9). When it is considered that the elderly population and chronic disease incidence are increasing in the society, there is a need for further research on low health literacy and the resulting high mortality.

In this study we aimed to evaluate the cognitive status of diabetes mellitus patients referred to an educator nurse for subcutaneous injection treatment education and to measure their health literacy level and compare the findings with treatment results.

\section{METHODS}

\section{Research Type and Population}

The study population consisted of Type2 diabetes mellitus patients over age 18 who was admitted to the SBU Bursa Yuksek Ihtisas Training and Research Hospital diabetes education outpatient clinic for insulin pen education between January 2018 and February 2018.

The Ministry of Health Istanbul Kartal Dr. Lutfi Kirdar Training and Research Hospital Clinical Research Ethics 
Committee approved the dissertation "Effect of Health Literacy on Treatment Results of Type-2 Diabetes Mellitus Patients Admitted for Insulin Pen Use Education" with its resolution and authorization no. 2017/ 514/ 118/ 15, 28.11.2017.

\section{Participants}

This study was conducted with 200 volunteer Type2 DM patients over age 18 receiving subcutaneous injection (insulin or exenatide) treatment who were admitted to the SBU Bursa Yuksek Ihtisas Training and Research Hospital diabetes education outpatient clinic between January 2018 - February 2018. Consent was obtained from these 200 individuals and the research was performed using a survey method.

\section{Research Inclusion Criteria}

Research inclusion criteria were: admission to the Diabetes Education Outpatient Clinic for insulin pen education, being a Type 2 DM patient, receiving insulin or exenatide treatment and accepting to participate in the study.

\section{Questionnaires}

A questionnaire interrogating socio-demographic characteristics of the patients, Standardized MiniMental State Examination to assess cognitive function and to distinguish dementia, and the Turkish version of the European Health Literacy Scale Questionnaire (HLS-EU-Q) were used in this research.

Anthropometric measurements, height and weight, were measured with standard measurement tools. The individuals were asked to take off their shoes during height measurement. It was ensured that patients were wearing light clothing during weight measurement. BMI: Body mass index value was calculated by dividing the patient's weight by the square of his/her height $\left(\mathrm{kg} / \mathrm{m}^{2}\right)$. Waist circumference was measured in standing position with an inelastic tape measure and the narrowest diameter between arcus costarum and processus spina iliaca anterior superior was accepted as the waist circumference.

The Mini Mental State Examination test form is comprised of eleven items under five main topics: orientation, registration, attention and calculation, recall and language, and is evaluated with a total score of 30 . Any score of 24 or more (out of 30 ) indicates normal cognition. Below this, scores can indicate severe ( $\leq 9$ points), moderate (10-18 points) or mild (19-23 points) cognitive impairment. In order to provide standardization in our study, we determined the limit for dementia as $23 / 24(\leq 23$; there is dementia).

The European Health Literacy Scale Questionnaire (HLS-EU-Q) form consists of 47 questions. Each of the 47 items is rated on a 4-point scale ( $1=$ very difficult, $2=$ difficult, $3=$ easy, $4=$ very easy). This scale is based on the principle of evaluating how "easy" or "difficult" the behavior specified in each item is, according to one's own perception.

Index scores were standardized on a scale between 0 and 50 ; " 0 "is the lowest health literacy, " 50 "is the highest health literacy, as shown in the formula below:

Formula: Index $=($ mean -1$) \times(50 / 3)$

Index: Index specific to the calculated person

Mean: Mean of each item answered

$\mathrm{HL}$ was divided into four categories according to the index values obtained:

(0-25) insufficient,

(>25-33) problematic - limited HL

(>33-42) sufficient HL

(>42-50) perfect $\mathrm{HL}$

\section{Statistical Analysis}


Conformity of the variables to normal distribution was analyzed with Shapiro Wilk test. Continuous variables are presented with median (minimum: maximum) and mean \pm standard deviation values. Categorical variables are presented as $\mathrm{n}$ (\%). In case of conformity of the variables to normal distribution according to the normality test results, independent paired-samples t test was used in comparison of two groups and in case of non-conformity of variables to normal distribution Mann Whitney $U$ test was used. Pearson chi-square test and Fisher's exact chi-square test were used in comparisons of categorical variables between groups. Internal consistency of the health literacy scale was analyzed with Cronbach alpha coefficient. The relationship between general health literacy score of the variables and mini-mental scores was analyzed with Spearman correlation coefficient. SPSS (IBM Corp. Released 2012. IBM SPSS Statistics for Windows, Version 21.0. Armonk, NY: IBM Corp.) program was used for statistical analysis and $p<0.05$ was accepted as statistically significant.

\section{RESULTS}

There were 127 female and 73 male participants. Mean age was calculated as $58.17 \pm 11.04$. Health literacy distribution of the participants is given in Table1. Total rate of the participants with insufficient/problematic general health literacy was calculated as $83 \%$. Dementia was detected in $23.80 \%$ of the participants $(n=47)$ (Figure1).

Table1. Health literacy distribution

\begin{tabular}{|l|l|l|l|l|}
\hline & InsufficientHL (\%) & $\begin{array}{l}\text { ProblematicHL } \\
(\%)\end{array}$ & Sufficient HL (\%) & Perfect HL(\%) \\
\hline General HL & $34.50 \%$ & $48.50 \%$ & $17 \%$ & $0 \%$ \\
\hline Health Care Service HL & $21.50 \%$ & $36 \%$ & $38.50 \%$ & $4 \%$ \\
\hline Disease Prevention HL & $55 \%$ & $33 \%$ & $12 \%$ & $0 \%$ \\
\hline Health Improvement HL & $42 \%$ & $47.50 \%$ & $10 \%$ & $0.50 \%$ \\
\hline
\end{tabular}

HL: Health literacy

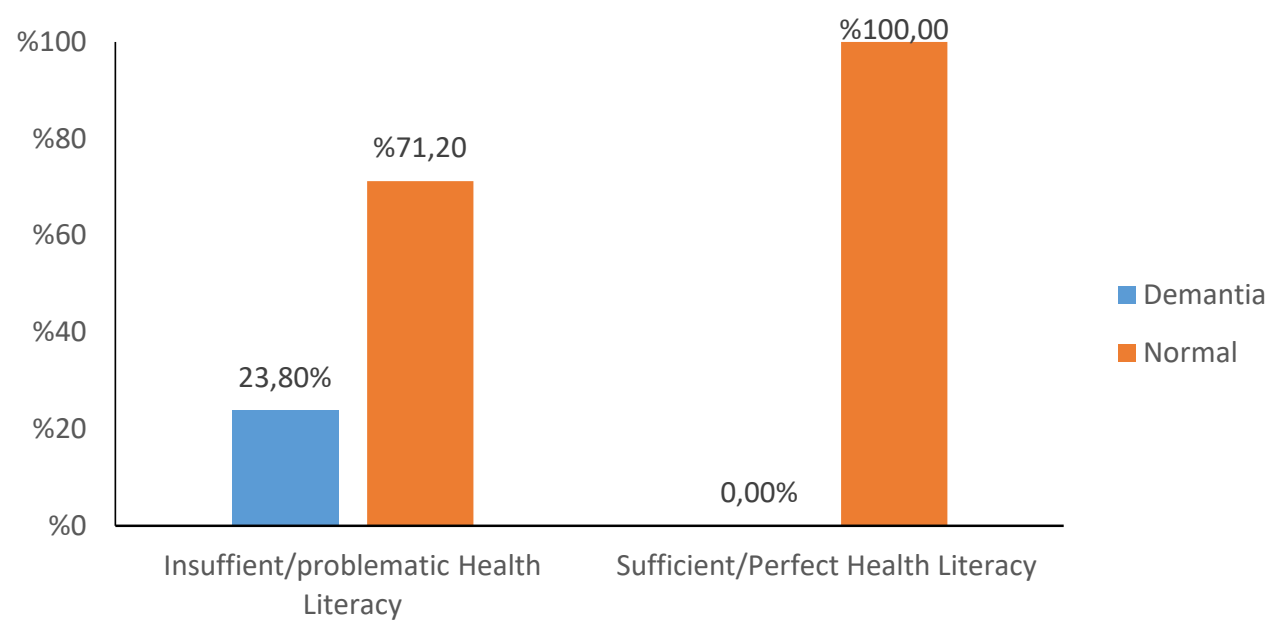

Figure1. Health literacy and mini-mental test score relationship 
No difference was detected between $\mathrm{HL}$ groups in the comparison of HbA1c levels $(p=0.277) \quad(T a b l e 2)$.

The percentage change was calculated to analyze the change in baseline measurements during control measurements. When related percentage change values were analyzed, it was seen that Hba1c levels of those with limited health literacy decreased to a rate of $9.94 \%$ while this decreased rate was $17.26 \%$ in those with sufficient health literacy. It was determined that the decrease in HbA1c values in the group with adequate health literacy following insulin pen education was greater than inadequate health literacy group $(p=0.025)$ (Table2 and Figure2).

Table2. Hba1c and health literacy relationship before and after insulin pen education

\begin{tabular}{|l|l|l|l|}
\hline & $\begin{array}{l}\text { Inadequate } \\
\text { Health Literacy } \\
(\mathbf{n = 1 6 6})\end{array}$ & $\begin{array}{l}\text { Adequate } \\
\text { Health Literacy } \\
(\mathbf{n = 3 4 )}\end{array}$ & $11.10 \pm 2.74$ \\
\hline HbA1c & $10.58 \pm 2.44$ & $8.96 \pm 2.01$ & $0.277^{\mathrm{a}}$ \\
\hline Control HbA1c & $9.19 \pm 2.13$ & $\begin{array}{l}-17.26 \% \\
(-42.65: 14.10)\end{array}$ & - \\
\hline $\begin{array}{l}\text { HbA1c } \\
\text { (Control } \rightarrow \text { First measurement) }\end{array}$ & $\begin{array}{l}(-9.94 \% \\
\mathbf{O . 0 2 5}^{\mathbf{b}}\end{array}$ \\
\hline
\end{tabular}

Data presented as mean Istandard deviation or median (minimum: maximum).

a: Independent paired sample t test, $b:$ Mann Whitney $U$ test

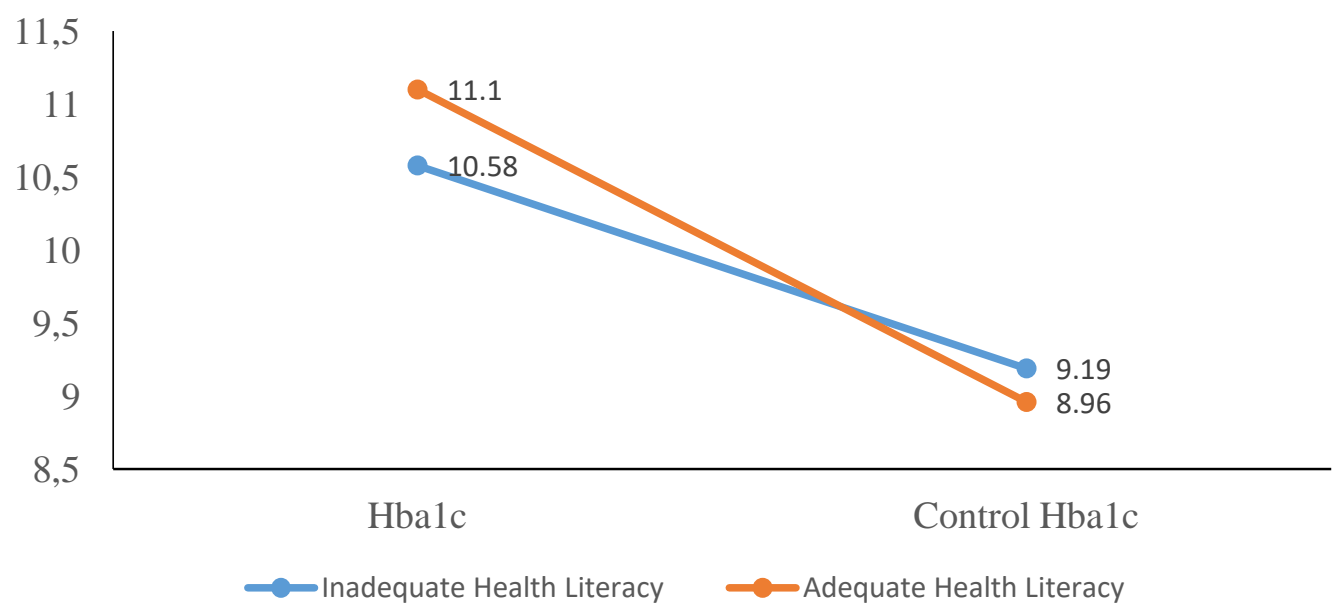

Figure2. HbA1c change and health literacy relationship

The percentage change was calculated to analyze the change in baseline measurements versus control measurements. When related percentage change values were analyzed, it was observed that $\mathrm{HbA1c}$ levels decreased $5.58 \%$ in the dementia group, whereas the decrease in the normal group was $13.04 \%$. The decrease in HbA1c level in the normal group following insulin pen education was greater than 
the patients with dementia $(p=0.006)$ (Table3 and Figure3).

Table3. HbA1c and dementia relationship before and after insulin pen education

\begin{tabular}{|l|l|l|l|}
\hline & DEMENTIA (n=47) & $\begin{array}{l}\text { NORMAL } \\
(\mathbf{n = 1 5 3})\end{array}$ & p-value \\
\hline HbA1c & $10(5.50: 15.80)$ & $11(5.40: 18.60)$ & $0.084^{\mathrm{b}}$ \\
\hline Control HbA1c & $9.10(4.70: 15.80)$ & $8.60(5.70: 15.20)$ & - \\
\hline $\begin{array}{l}\text { HbA1c } \\
\text { (Control } \rightarrow \text { First measurement) }\end{array}$ & $\begin{array}{l}(-5.88 \% \\
(-40.16: 24.41)\end{array}$ & $-13.04 \%$ \\
$(-55.41: 53.33)$ & $\mathbf{0 . 0 0 6}^{\mathbf{b}}$ \\
\hline
\end{tabular}

Data presented as median (minimum: maximum).

b: Mann Whitney $U$ test

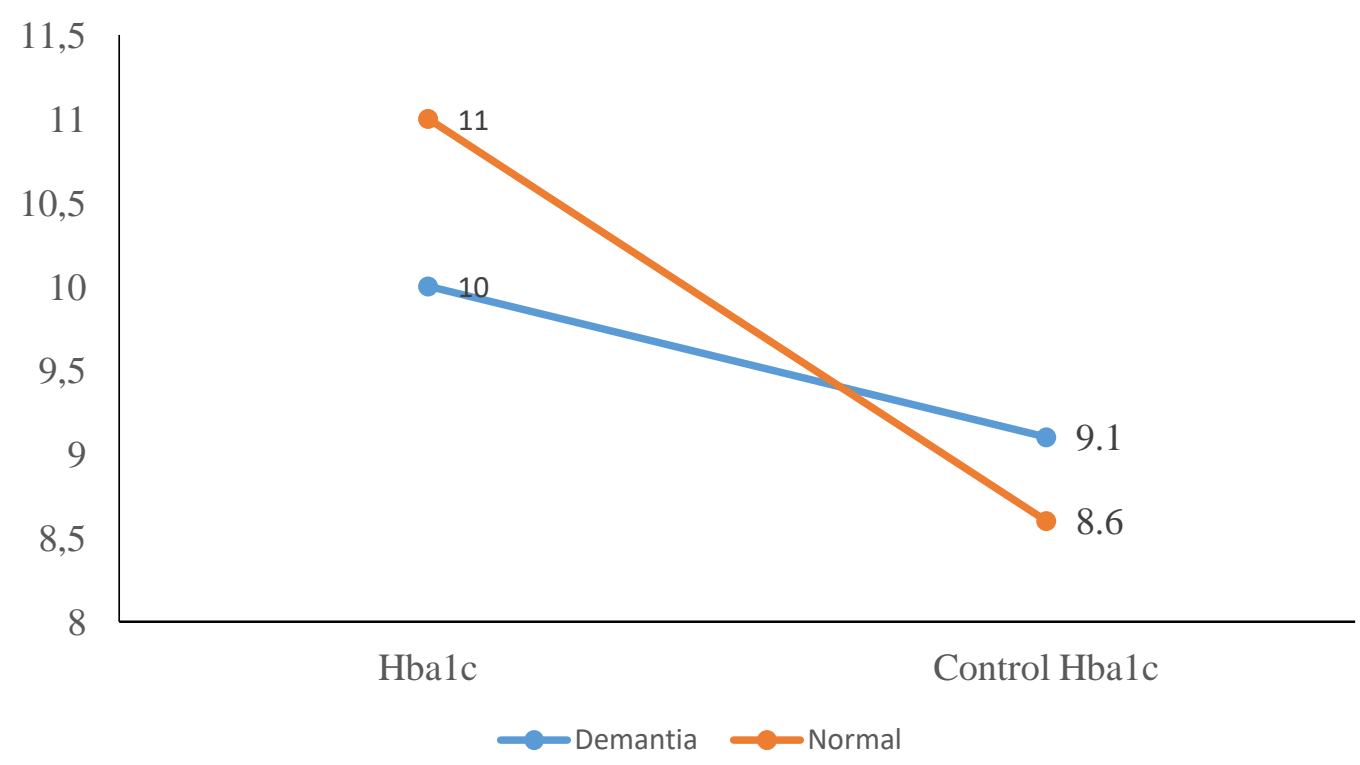

Figure3. HbA1c change and dementia relationship

A reverse relationship was detected between the increase in general health literacy score and number of hospitalizations. Increase in health literacy score corresponded to a decrease in the number of hospitalizations (Table4). 
Table4. Relationship between health literacy and hospitalization, hypoglycemic attack and admission to emergency service before and after education

\begin{tabular}{|l|l|l|}
\hline \multirow{2}{*}{$\mathbf{n}=\mathbf{2 0 0}$} & \multicolumn{2}{l}{} \\
& \multicolumn{2}{l|}{ GENERAL HEALTH LITERACY SCORE } \\
\cline { 2 - 3 } & $\mathbf{r}_{\mathrm{s}}$ & $\mathbf{p}$-value \\
\hline Number of hospitalizations & -0.21 & $\mathbf{0 . 0 0 2}$ \\
\hline Number of hypoglycemic attacks & 0.02 & 0.754 \\
\hline Number of admissions to emergency & -0.10 & 0.155 \\
\hline Number of admissions to emergency after education & -0.04 & 0.584 \\
\hline
\end{tabular}

There was also a reverse relationship between the the hospital (Table5). A reverse relationship was increase in mini-mental score and number of days in the hospital. Increase of mini-mental score corresponded to a decrease in the number of days in detected between the increase in mini-mental score and the number of admissions to the emergency. The increase in mini-mental score corresponded to a decrease in the number of admissions to the emergency service (Table5).

Table5. Relationship between mini-mental test score and hospitalization, hypoglycemic attack and admission to emergency service before and after education

\begin{tabular}{|c|c|c|}
\hline \multirow{2}{*}{$\mathbf{n}=\mathbf{2 0 0}$} & \multicolumn{2}{|c|}{ MINI-MENTAL SCORE } \\
\hline & $\mathbf{r}_{\mathrm{s}}$ & p-value \\
\hline Number of hospitalizations & -0.15 & $\mathbf{0 . 0 3 0}$ \\
\hline Number of hypoglycemic attacks & -0.04 & 0.533 \\
\hline Number of admissions to emergency & -0.14 & 0.048 \\
\hline Number of admissions to emergency after education & -0.03 & 0.724 \\
\hline
\end{tabular}

$r_{s}:$ Spearman correlation coefficient

\section{DISCUSSION}

The total rate of participants with insufficient/limited health literacy was $83 \%$ at the end of the study. In the same population, the dementia incidence was $24 \%$ and there was a direct relationship between general health literacy status and mini-mental test scores. The decrease in HbA1c levels for the patients receiving insulin pen education was greater in the group with sufficient health literacy and without dementia.

In a study conducted in Turkey with the participation of 4924 individuals randomly selected from 23 Turkish provinces, based on the European Health Literacy Scale (HLS-EU), it was found that $64.6 \%$ of the 
Turkish society was in the category of "insufficient" $(24.5 \%)$ or "problematic" (40.1\%) health literacy (10).In the study performed by Ozdemir et al., the rate of insufficient or problematic health literacy in adults was $41.3 \%$ according to REALM and $71.9 \%$ according to the NVS scale (11). In a study compiling research based on different scales, insufficient health literacy was between $22-29 \%$ (12). In another systematic compilation, the prevalence of insufficient health literacy was reported to be between $34-59 \%$ (10). Values we obtained in our study are higher than the previous studies. The reason for this may be the higher mean age of the patients.

It was shown that limited health literacy was common in individuals with a chronic disease diagnosis $(13,14)$. In studies performed in America including hypertensive and diabetes patients, health literacy levels of the patients were assessed using a final vital signs scale and their mean scores were, respectively, $3.00 \pm 1.90$ and $2.87 \pm 1.80(15,16)$. It was found that $45.1 \%$ of the hypertension patients evaluated in a study conducted in Singapore had a sufficient level of HL and $69.0 \%$ of the patients assessed in another study in America had a sufficient $\mathrm{HL}$ level $(17,18)$. In another study with diabetes patients in the Netherlands, $28 \%$ of the patients were reported to have a sufficient $\mathrm{HL}$ level (19). In our study, HL levels of the diabetes patients were assessed with HLS-EU-Q and a sufficient $\mathrm{HL}$ level was detected in only $17 \%$ of the patients.

In a study analyzing reasons for hospitalization of DM patients, the top three items were cardiovascular disease, pulmonary system disease and diabetic circumstances (20). According to a study conducted in Turkey by Akin et al., the hospitalization rate of patients admitted to the emergency service was $23.8 \%$ (21). When acute complications except comorbid conditions among hospitalization reasons were analyzed, insulin usage and age were found as significant risk factors in the literature. It was found in particular that $64.5 \%$ of the hypoglycemia patients did not take any measurements, only a small number were admitted to the emergency service after taking measurements and only $16 \%$ of the patients were hospitalized (22). We found in our study that an increase in the $\mathrm{HL}$ level corresponded to a decrease in hospitalization frequency. Besides this, we observed that there was no significant difference between the number of hypoglycemic attacks and number of admissions to the emergency service before and after the education and general $\mathrm{HL}$ score level.

In a study evaluating self-administration of insulin, it was found that all diabetic patients made mistakes in insulin administration. For example, hyperglycemia can occur in case of long acting insulin injections instead of short acting insulin, or hypoglycemia can occur in case of short acting insulin injections instead of long acting insulin (23). These results can be caused by the patients' lack of information about their insulin types and characteristics. In a study performed in our country it was found that none of the patients knew the insulin type they used (24). Another study showed that failure to adjust the insulin dose was related to individual insufficiency (25). It has been demonstrated that the injection method used in diabetes treatment affects the patient's ability to accept the insulin treatment, his/her quality of life, barriers in insulin treatment and his/her compliance with medication (26). Besides this, it was shown in many clinical studies that amelioration in metabolic control and decrease in HbA1c level occurs with the increase in compliance to the treatment (27-30). In the study of Rhee MK et al. analyzing the relationship between the number of controls and compliance with the treatment and HbA1c, a decrease of $0.35 \%$ in HbA1c was observed with an increase of $25 \%$ in compliance with treatment within one year, and a decrease of $0.12 \%$ in $\mathrm{HbA1c}$ was seen with each additional control (28). 
Similarly, in the studies of Schectman et al. (29) and Kravitz et al. (30), it was indicated that there was a greater decrease in $\mathrm{HbA1c}$ levels of patients with high compliance rates. Kravitz et al. observed in this study that there was a decrease of $0.4 \%$ in $\mathrm{HbA} 1 \mathrm{c}$ with each $25 \%$ increase in compliance with the medication in 20 months follow-up. In a study on type 1 diabetics, it was seen that skipping two meals with insulin per week was associated with an increase of $0.5 \%$ in HbA1c (31). We aimed to increase patient compliance with medication by giving them insulin pen education. Thus, a decrease was detected in HbA1c levels in both groups following 3 months of follow-up, whereas the decrease was statistically more significant in the patient group with sufficient health literacy. Similar to our study, the higher the level of knowledge of patients on diabetes and on medical treatment they receive, the greater the compliance with the treatment and better $\mathrm{HbA1c}$ values are achieved (27).

In a thesis study conducted in Turkey on Alzheimer type dementia patients, it was found that the group of patients with Alzheimer type dementia was more unsuccessful in systematic and accurate thinking, mental skills and reasoning, and had slower response rates and psychomotor speed processes compared to the control group. The discrepancies detected in this study, similar to our study, were from lower health literacy in dementia patients compared to nondementia patients (32).

The presence of more than one chronic disease in elderly individuals with dementia has been reported in the literature, whereas it has also been mentioned that this patient group with impaired cognition and functionality experienced additional problems due to their inability to manage their chronic diseases accurately (33-35). In the study conducted by Rudolp et al. (2010), Alzheimer patients and other elderly groups were compared and it was reported that falls, wrong medication usage, dehydration and malnutrition were quite frequent problems that Alzheimer patients faced and which may reach to a life-threatening extent. It was also mentioned that early diagnosis is vital in order to prevent such negative circumstances (34). For these reasons, we observed in our study as well that dementia patient admission to the emergency service and the number of hospitalizations was higher. We predicted that this insufficiency in the follow-up of chronic diseases would lead to impairment in glycemic values, a decrease in the awareness of complications that may develop in diabetes follow-up of dementia patients and an increase in diabetic complications due to skipping screening programs. In our study, in which we compared the relationship between dementia and retinopathy, neuropathy, nephropathy and CAD among diabetic complications, the incidence of retinopathy, nephropathy and neuropathy was greater in the group with dementia, but the difference was not statistically significant.

No difference was detected between the HbA1c levels of patients with and without dementia, whereas it was observed that patients without dementia had a better understanding of insulin pen education and a more significant low level of HbA1c. We assume that episodic memory impairment, registration problems and the corresponding inability to learn new and repeated trials with dementia caused this discrepancy $(36,37)$. Moreover, according to some studies, the decrease in arithmetic skills of dementia patients could lead to a failure in measuring their blood glucose levels and adjustment of insulin doses, and thus to a smaller decrease in their HbA1c levels $(38,39)$.

\section{LIMITATIONS OF THE STUDY}

This was a mono-centered study. It was performed in the diabetes education outpatient clinic of Bursa Yuksek Ihtisas Training and Research Hospital and 
reflects the results of this province only and these results cannot be generalized.

We conducted this research with diabetes patients who were admitted to the diabetes education outpatient clinic for insulin pen education. In case injections were performed by relatives of patients when the patients were unable to perform it themselves, the health literacy levels of the patient helpers may have affected the treatment results.

\section{CONCLUSION}

As a conclusion from the study, the total rate of participants with insufficient/problematic general health literacy was $83 \%$ according to HL-EU-Q. This rate was assessed to be very high compared to previous studies. The degree of decrease in HbA1c levels of the patients who received insulin pen education was better in the group with sufficient health literacy and without dementia. Health literacy levels and sufficient cognitive function in diabetes mellitus cases would increase the efficiency of patient education.

\section{CONFLICT OF INTEREST}

The authors declare that they have no conflict of interest.

\section{References}

1. Durmaz AA. Diyabette hemşirelik bakımı. Kronik Hastalıklarda Bakım. İntertıp Tıbbi Yayıncılık, İzmir; 2002.

2. Nutbeam D. Health promotion glossary. Health Promot. Int. 1998;13 (4):349-64.

3. Baker DW, Wolf $M$, Feinglass $S$, Thompson JA. Health Literacy, Cognitive Abilities, and Mortality Among Elderly Persons._Journal of General Internal Medicine, 2008;_23(6) :723-726.
4. Baker DW, Parker R, WilliamsM, ClarkW. Health Literacy and the Risk of Hospital Admission._Journal of General Internal Medicine1998; 13(12): 791-8.

5. Davis T, Long SW, JacksonRH, Mayeaux EJ, George RB, Murphy PW et al. Practical Assessment of Adult Literacy in Health Care, Health Education and Behavior 1998; 25(5): 613-24.

6. Williams MV, Baker DW, Parker RM and Nurss JR. Relationship ofFunctional Health Literac to Patients' Knowledge of Their Chronic Disease. A Study of Patients with Hypertension and Diabetes. Archives of Internal Medicine, 1998;158(2): 166-72.

7. Powell CK, Hill EG, Clancy DE. The relationship between health literacy and diabetes knowledge and readiness to take health actions. Diabetes Educator. $2007 ; 33(1): 144-51$.

8. Dahlke AR, Curtis LM, Federman AD, Wolf MS. The Mini Mental Status Exam as a Surrogate Measure of Health Literacy._Journal of General Internal Medicine 2014; 29(4): 615-20.

9. Gazmararian J, Baker D, Parker R, Blazer DG. A Multivariate Analysis of Factors Associated with Depression: Evaluating the Role of Health Literacy as a Potential Contributor._Archives of Internal Medicine 2000;160(21):3307-14.

10. Tanrı̈ver MD, Yıldıım HH, Ready FND, Çakır B, Akalın HE. Türkiye Sağlık Okuryazarlığı Araştırması; 2014.

11. Özdemir $H$, Alper $Z$, Uncu $Y$, Bilgel $N$. Health literacy among adults: a study from Turkey. Health Education Research, 2010; 25(3): 464-77.

12. Berkman ND, Davis TC, McCormack L. Health Literacy: What is it?._Journal of Health Communication, 2010: 15(2); 9-19.

13. Pandit AU, Tang JW, Bailey SC, et al. Education, literacy, and health: Mediating effects on hypertension knowledge and control. Patient Educ and Couns 2009; 75: 381-385

14. Powers BJ, Olsen MK, Oddone EZ, Thorpe CT, Bosworth HB. Literacy and blood pressure - do healthcare systems influence this relationship? A crosssectional study. BMC Health Serv Res 2008; 8 (219): 1-9.

15. Kirk JK, Grzywacz JG, Arcury TA, et al. Performance of health literacy tests among older adults with diabetes. J Gen Intern Med 2011; 27(5): 534-540.

16. Pendlimari R, Holubar SD, Hassinger JP, Cima RR. Assessment of colon cancer literacy in screening colonoscopy patients: A validation study. J Surg Res 2012; 175: 221-226. 
17. Ko $Y$, Balasubramanian TD, Wong $L$, et al. Health literacy and its association with disease knowledge and control in patients with hypertension in Singapore. Int J Cardiol 2013; 108: 116-117.

18. Persell SD, Osborn CY, Richard R, Skripkauskas $S$, Wolf MS. Limited health literacy is a barrier to medication reconciliation in ambulatory care. J Gen Intern Med 2007; 22(11): 1523-1526.

19. Fransen MP, Van Schaik TM, Twickler TB, EssinkBot ML. Applicability of internationally available health literacy measures in the netherlands. Journal of Health Communication: International Perspectives 2011; 16(3):134-149.

20. Al-Adsani AMS. Reasons for hospitalizations in adults with diabetes in Kuwait. International Journal of Diabetes Mellitus,2015:3-1:65-69

21. Akın $S$, Kazan $S$, Yalçın C, Erdoğan $M$, Aydın KD, Tekçe M, Aliustaoğlu M.Tip 2 Diyabette Hastalık Yaşı ile Acil Servis Başvurularında Yatış Oranlarının Karşılaştııılması, J Kartal TR. 2015;2 6(3): 207-210

22. Temurtaş, M. Eskişehir Osmangazi Üniversitesi sağlık uygulama ve araştırma hastanesi acil servisine başvuran diyabetes mellitus tanılı hastaların acil servis başvuru nedenlerinin değerlendirilmesi (tez). Eskişehir: Osmangazi Üniversitesi; 2016.

23. Özcan Ş. İnsulin Tedavisinin Yönetimi, S.Erdogan (Ed.), İçinden: Diyabet Hemşireliği: Temel Bilgiler.(sy: 40-54). İstanbul. Yüce Basımevi; 2002.

24. Özdemir Ü, Özemir H, Kumbasar C, Kadakal M, Şahin Z, Saydam A. Diabetes mellituslu hastaların insülin uygulamalarına ilişkin bilgi düzeylerinin saptanması. Poster, 10. İç hastalıkları Kongresi (Kongre Kitabı). Antalya. 2008;15-19 Ekim, 364.

25. Redon J, Sornı G, Gonzalez-Molına A, Caballero M, Baguena J. Accuracy of insulin injection in elderly patients. Br Med J (Clin Res Ed) 1983;287(6407), 1762.

26. KM Stewart, MF Wilson, JM Rider. Insulin delivery devices. Journal of Pharmacy Practice 2004; 17: 20-28

27. Al-Qazaz HKh, Sulaiman SA, Hassali MA, Shafie AA, Sundram S, Al-Nuri R, Saleem F. Diabetes knowledge, medication adherence and glycemic control among patients with type 2 diabetes. Int J Clin Pharm. 2011; 33(6): 1028-1035. doi: 10.1007/s11096-011-9582-2. Epub 2011 Nov 15.
28. Rhee MK, Slocum W, Ziemer DC, Culler SD, Cook CB, El-Kebbi IM, Gallina DL, Barnes C, Phillips LS Patient adherence improves glycemic control. Diabetes Educ. 2005; 31(2): 240-250.

29. Schectman JM, Nadkarni MM, Voss JD. The association between diabetes metabolic control and drug adherence in an indigent population. Diabetes Care 2002;25(6): 1015-1021.

30. Kravitz RL, Hays RD, Sherbourne CD et al. Recall of recommendations and adherence to advice among patients with chronic medical conditions. Arch Intern Med.1993; 153(16): 1869 -1878.

31. Burdick J, Chase HP, Slover RH, Knievel K, Scrimgeour L, Maniatis AK, Klingensmith GJ. Missed insulin meal boluses and elevated hemoglobin A1C levels in children receiving insulin pump therapy. Pediatrics 2004; 113(3): 221- 224.

32. Elif Ünal, Onur Akan, Serap Üçler S.B. Okmeydanı Eğitim ve Araştırma Hastanesi, Nöroloji Kliniği Okmeydanı Tıp Dergisi 31(Ek sayı):45-51, 2015

33. Sanderson M, Wang J, Davis D. Comorbidity associated with dementia. Am J Alzheimer Dis Oth Demen, 2002;17;73

34. Rudolph J, Zanin M., Jones R. Hospitilization in community dwelling persons with Alzheimer's disease: frequency and causes. JAGS, 2010.

35. Bynum JPW, Rabins PV, Weller $W$ ve ark. The relationship between a dementia diagnosis, chronic illness, medicare expenditures, and hospital use. JAGS, 2004;52(2), 187- 194. 91.

36. Levinoff JE, Verret L, Akerib V, Phillips, AN, Babians L, Kelner N. ve Chertkow, H. Cognitive Estimation Impairment in Alzheimer Disease and Mild Cognitive Impairment. Neuropsychology, 2006; 20 (1):123-132.

37. Butters N, Salmon DP ve Cullum CM. Differentiation of amnesic and demented patients with the Wechsler memory scale-revised. Clinical Neuropsychology, 1988; 2:133-144.

38. Kong J, Wang C, Kwong K, Vangel M, Chua E, Gollub R. The neural substrate of arithmetic operations and procedure complexity. Brain Res. Cogn. Brain Res. 2005; 22.397-405.

39. Gruber O, Indefrey B, Steinmetz $H$, Kleinschmidt A. Dissociating neural correlates of cognitive components in mental calculation. Cereb. Cortex 2001;11:350-359. 